\title{
The Effect of Thermal Conductance of Evaporator on Performance of a Two Stage Adsorption Chiller (Reheat) with Different Mass Allocation
}

\author{
T. Sultana ${ }^{{ }^{*}}$ and M.Z.I. Khan ${ }^{2}$ \\ Institute of Education and Research, Dhaka University, Dhaka-1000, Bangladesh \\ Department of Mathematics, Bangladesh University of Engineering and Technology, Dhaka-1000, Bangladesh \\ (Received: 5 September 2013; Accepted: 5 February 2014)

\begin{abstract}
Now a days, adsorption heat pumps receive considerable attention as they are energy savers and environmentally benign. Silica gel/water based adsorption cycles have a distinct advantage in their ability to be driven by heat of near-ambient temperature so that waste heat below $100{ }^{\circ} \mathrm{C}$ can be recovered. One interesting feature of refrigeration cycles driven by waste heat is that they do not use primary energy as driving source. In the present paper, an analytic investigation of a two-stage adsorption refrigeration chiller using re-heat with different mass allocation was performed to determine the influence of the thermal conductance of evaporator as well as the heat source temperature on the chiller performance. Result shows that cycle performance is strongly influenced by large thermal conductance values of the evaporator. Besides it is observed that the chilled water outlet has lower value for comparatively higher value of heat source temperature.
\end{abstract}

Keywords: Two-stage adsorption chiller using re-heat; Thermal conductance; Performance

\section{Introduction}

The quest to accomplish a safe and comfortable environment has always been one of the main preoccupations of the sustainability of human life. Widespread efforts are currently underway to utilize available energy resources efficiently by minimizing waste energy and develop replacements for the traditionally refrigerants (CFCs and HCFCs), which contribute to ozone depletion and greenhouse warming. Accordingly, during the last few decades research aimed at development of thermally powered adsorption cooling technologies has been intensified. They offer double benefits of reductions in energy consumption, peak electrical demand in tandem with adoption of environmentally benign adsorbent/ refrigerant pairs such as zeolite/water ${ }^{1}$, activated carbon/ ammonia ${ }^{2}$, activated carbon/ methanol ${ }^{3}$ and silica gel/water ${ }^{4}$ without compromising the desired level of comfort conditions. It is well known that the performance of adsorption cooling/ heating system is lower than that other heat driven heating/ cooling systems specially, absorption system provided that the available heat source temperature is at $75^{\circ} \mathrm{C}$ or higher. From this context, many authors proposed and / or investigated the adsorption cooling and heating system to improve the performance. Meunier ${ }^{5}$ investigated the system performance of cascading cycle in which an active/methanol cycle is topped by zeolite/water cycle. To improve the value of Coefficient Of Performance (COP), Shelton et al. ${ }^{6}$ proposed thermal wave regenerative adsorption heat pump. In a similar effort, Critoph ${ }^{7}$ proposed a forced convection adsorption cycles. Pons and Poyelle ${ }^{8}$ investigated the effect of mass recovery process in convectional two bed adsorption cycle to improve the cooling power. Later, Wang $^{9}$ showed the mass recovery process for COP and SCP values. Few cycles, however, are proposed to utilize relatively low temperature heat source. To utilized low temperature waste heat source between $40^{\circ} \mathrm{C}$ and $60^{\circ} \mathrm{C}$, Saha et al. ${ }^{10}$ proposed and examined experimentally a three-stage adsorption chiller with silica gel/water pair. Saha et al. ${ }^{11}$ also introduce a two-stage adsorption chiller and the required driving heat source temperature is validated experimentally. In the two stage chiller, it is possible to get effective cooling with driving heat source temperature bellow $60^{\circ} \mathrm{C}$. A novel adsorption chiller, namely, 're-heat two stage' chiller is introduced by Alam et al. ${ }^{12}$ and he has shown that the chiller is able to exploit the heat source of temperature between $50^{\circ} \mathrm{C}$ and $90^{\circ} \mathrm{C}$ and can produce effective cooling. Khan et al. ${ }^{13}$ studied the effect of thermal conductance and adsorbent mass on a two-stage adsorption chiller using re-heat scheme. Later, Khan et al. ${ }^{14}$ investigated the performance evaluation of multi-stage, multi-bed adsorption chiller employing re-heat scheme. Saha, et al. ${ }^{15}$ investigated the influence of the thermal conductance of sorption elements (adsorber/ desorber, evaporator and condenser) on the performance of a silicagel-water advanced adsorption chiller. They considered the thermal capacitance ratio of the adsorbent and metal of the adsorber/desorber heat exchanger. Recently, Farid et al. ${ }^{16}$ studied numerically the performance investigation of a silica gel/water based on two-stage, four-bed adsorption chiller with different mass allocation. In the present study, the adsorption chiller investigated the effect of thermal conductance of evaporator as well as the heat source temperature on cooling capacity (CC), the co-efficient of performance(COP), chilled water outlet keeping the different mass ratio between upper and bottom beds (3:2 mass ratio) fixed.

\section{Physical Model}

The design criteria of the two-stage adsorption chiller using re-heat is almost similar to that of a two-stage adsorption chiller without re-heat which is developed by Alam et al. ${ }^{17}$. Operational strategy of a conventional two-stage chiller, however, is completely different from operational strategy of a conventional two-stage chiller. In two-stage adsorption chiller, the evaporating pressure lift is divided into two consecutive pressure lifts to exploit low heat source temperature by introducing four adsorbent beds. In the twostage adsorption chiller using re-heat, the evaporating pressure (temp.) lift, however, can be divided into different ways from the conventional two-stage chiller. If one bed is in the end position of adsorption-evaporation process and another bed is in the end position of desorption-condensation

*Auther for Correspondance. e-mail:labsachin@gmail.com 
process, those two beds can be connected with each other by continuing cooling and heating and that can be done in the two bed conventional adsorption chiller which is known as the mass recovery process presented by Akahira et al. ${ }^{18}$. In this time, another two beds are connected with condenser and evaporator to continue cooling effects to complete one full cycle in re-heat scheme, all adsorbent beds pass through six consecutive steps: desorption, mass recovery process with heating, pre-cooling, adsorption, mass recovery process with cooling and pre-heating.

The two-stage adsorption chiller using re-heat comprises four adsorbent beds, one condenser, one evaporator, and metallic tubes for hot, cooling and chilled water flows as shown in Fig. 1. In a conventional two stage chiller, lower two beds never interact with the condenser and upper two beds never interact with the evaporator. However, in the two- stage adsorption chiller using re-heat, all beds undergo through all process and interact with the condenser and evaporator. The chiller can be operated in different strategies. However, only one strategy has been considered in the present study. the chiller has 10 modes, mode- $\mathrm{A}, \mathrm{B}$, C, D, E, F, G, H, I and J (Table 1). Mode A, B, C and evaHex-2 is in adsorption process and cond-Hex-1 is in desorption process. In the adsorption-evaporation process, refrigerant (water) in evaporator is evaporated at evaporation temperature, $T_{\text {eva }}$ and seized heat, $Q_{\text {eva }}$ from the chilled water. The evaporated vapor is adsorbed by adsorbent (silica gel), at which cooling water removes the adsorption heat, $\mathrm{Q}_{\mathrm{ads}}$. the desorber (Hex-1) is heated up to the temperature $\left(\mathrm{T}_{\text {des }}\right)$ by heat $\mathrm{Q}_{\text {des }}$, provided by the driving heat source. The resulting refrigerant is cooled down by temperature $\left(\mathrm{T}_{\text {cond }}\right)$ in the condenser by the cooling water, which removes heat, $\mathrm{Q}_{\text {cond }}$. In Mode A, adsorber (Hex-4) is connected with desorber (Hex-3) through pipe with

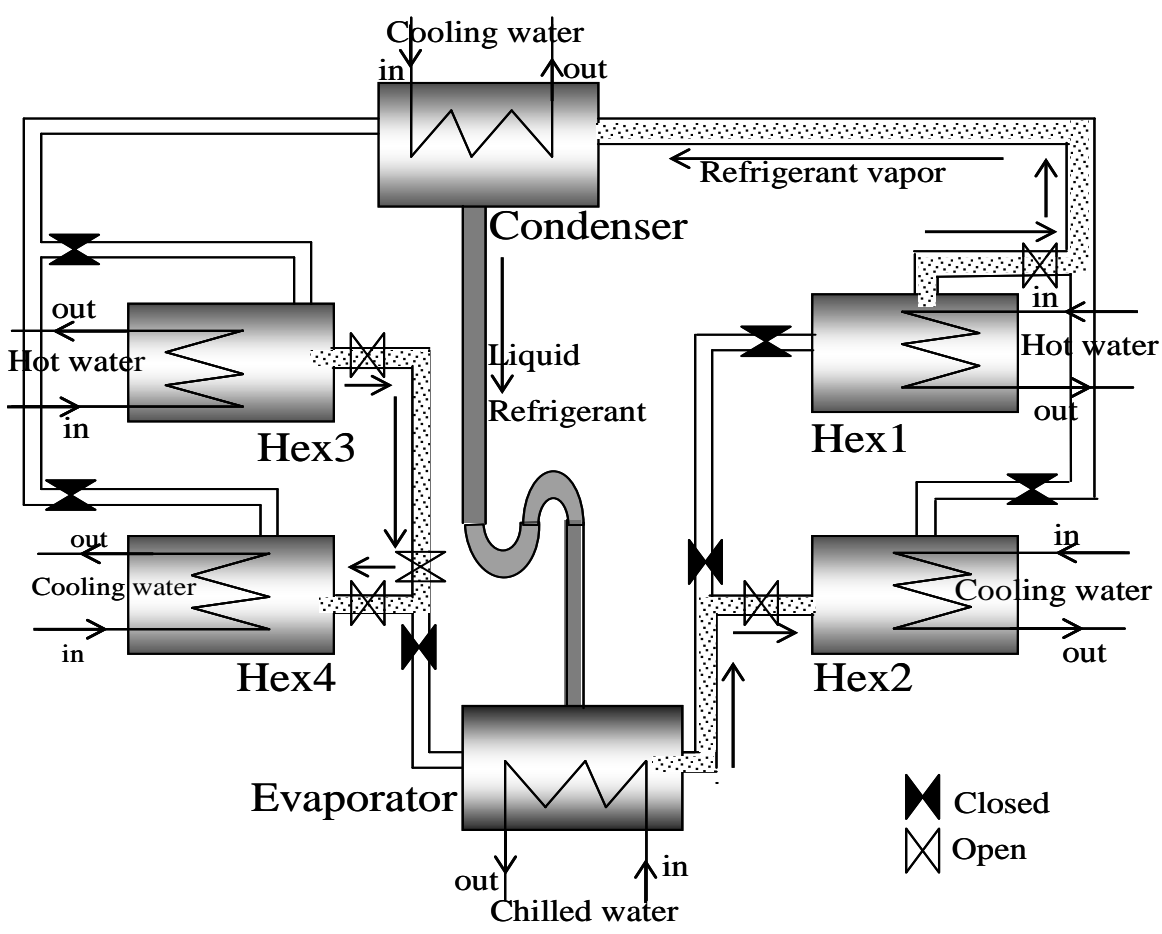

Fig.1. Schematic of a re-heat two-stage chiller

continuing cooling water in Hex-4 and hot water in Hex-3. It is noted that, at the beginning of mode A, Hex-4 was in the end position of evaporation-adsorption process and Hex3 was in the end position of desorption-condensation process. Due to higher pressure difference at Hex-3 and Hex-4 in mode A, the refrigerant mass circulation will be higher than that of conventional two stages. This will lead the chiller to provide better performance. In mode $B$, adsorber (Hex-4) is heated up by hot water and the desorber (Hex-3) is cooled down by cooling water. Mode B is warm up process for Hex-4 and Hex-3.

When the pressure of adsorber (Hex-3) and desorber (Hex4) are nearly equal to the pressure of evaporator and condenser respectively, Hex-3 and Hex-4 are connected to evaporator and condenser respectively to flow the refrigerant. This mode is denoted as mode C. in mode C,
Hex-4 works as desorber and hex-3 works as adsorber and this process will continuing up to mode E. Om Mode D, Hex-2 is at the end position of adsorption-evaporation process and Hex-1 is at the end position of desorptioncondensation process. And are connected with each other continuing cooling water and hot water respectively. When the pressure (temperature) of both Hex-1 and Hex-2 are nearly equal, the warm up process will start, called mode E. In Mode E, Hex-2 is heated up by hot water, and cooling water cools down the Hex-1. When the pressure of Hex-1 and Hex-2 are nearly equal to the pressure of evaporator and condenser respectively, then Hex-1 and Hex-2 are connected to evaporator and condenser respectively to flow the refrigerant. This connection will continue up to mode F, G and $\mathrm{H}$ for Hex-1 and Hex-2. In mode F, Hex-3 (at the end position of adsorption-evaporation process) and Hex-4 is at 
the end position of desorption-condensation process) are connected worth each other continuing cooling water and hot water respectively. When the pressure (temperature) of both Hex-3 and Hex-4 are nearly equal, the warm up process will start, called mode G. In Mode G, Hex-3 is heated up by hot water, and cooling water cools down the Hex-4. When the pressure of Hex-3 and Hex-4 are nearly equal to the pressure of evaporator and condenser respectively, then Hex-3 and Hex-4 are connected to evaporator and condenser respectively to flow the refrigerant. This connection will continue up to mode $\mathrm{H}$, I and $\mathrm{J}$ for Hex-3 and Hex-4. In mode I, Hex-1 (at the end position of adsorption-evaporation process) and Hex-2 is at the end position of desorption-condensation process) are connected worth each other continuing cooling water and hot water respectively. When the pressure (temperature) of both Hex-1 and Hex-2 are nearly equal, the warm up process will start, called mode J. In Mode J, Hex-1 is heated up by hot water, and cooling water cools down the Hex- 2 . The mode $\mathrm{J}$ is the last process and after this mode, all return to mode A (Table-1). The values adapted in simulation are presented in Table 2 and Table 3.

Table 1. Operational strategies of a two-stage chiller with re-heat

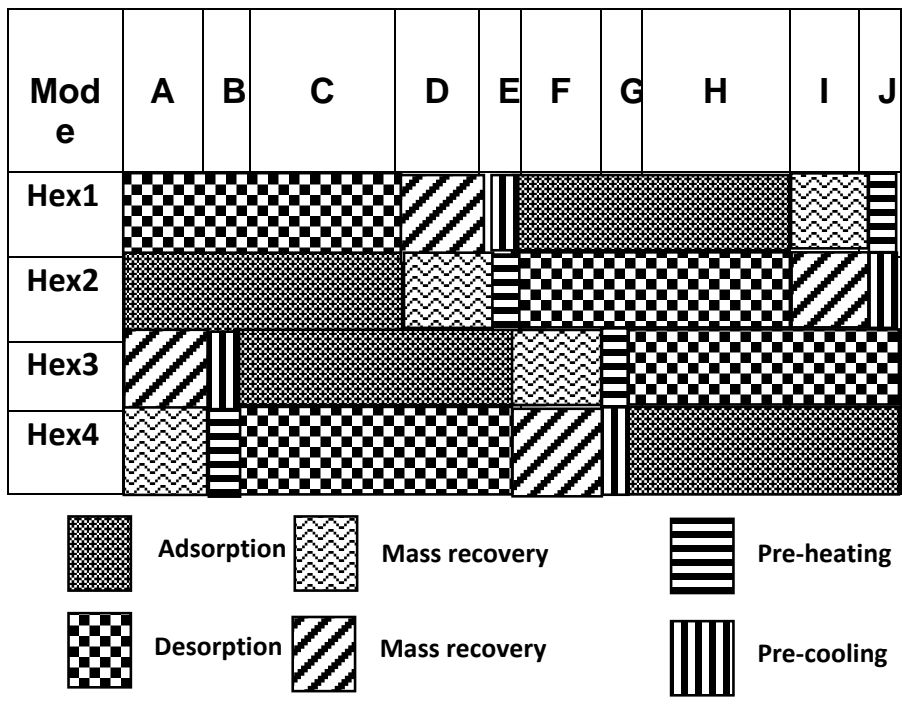

\section{Mathematical Model}

Energy balance for the adsorber/desorber

Adsorption and desorption heat balances ${ }^{10}$ are expressed by identical equations, where heat transfer fluid (water) temperature terms $T_{\text {in }}$ and $T_{\text {out }}$ indicate cooling water upon adsorption and hot water upon desorption. T stands for bed temperature. In addition, the adsorbent bed temperature, pressure and concentration are assumed to be uniform all over the adsorbent bed. The specific of refrigerant (water) in liquid phase is taken as our system works in low the concentration range. The heat transfer and energy balance equations for the adsorbent beds can be described as follows:

$$
\begin{aligned}
& T_{\text {out }}=T+\left(T_{\text {in }}-T\right) \exp \left(-\frac{U_{\text {hex }} A_{\text {hex }}}{m_{w} c_{w}}\right) \\
& \frac{d}{d t}\left\{\left(w_{s} c_{s}+w_{s} c_{w} q+w_{\text {hex }} c_{\text {hex }}\right) T\right\}=w_{s} Q_{s t} \frac{d q}{d t}- \\
& \delta w_{s} c_{w}\left\{\gamma\left(T-T_{\text {eva }}\right)+(1-\gamma)\left(T-T_{w v}\right)\right\} \times \frac{d q}{d t}+ \\
& \dot{m}_{w} c_{w}\left(T_{\text {in }}-T_{\text {out }}\right)
\end{aligned}
$$

where $\delta= \begin{cases}0, & \text { desorption process } \\ 1, & \text { adsorption process }\end{cases}$

and

$$
\gamma=\left\{\begin{array}{cc}
1, & \text { bed is connected with evaporator } \\
0, & \text { bed is connected with another bed }
\end{array}\right.
$$

In governing equations (1) and (2), $T_{\text {out }}$ and $T_{\text {in }}$ are the outlet and inlet temperature of the water respectively, $T_{\text {eva }}$ and $T_{w v}$ are the temperature of the evaporator and water vapor respectively, $U_{h e x}$ and $A_{h e x}$ are the heat transfer coefficient and area of the heat exchanger respectively, $w_{s}$ is the weight of the silica gel, $c_{w}$ and $c_{s}$ are the specific heat of water and silica gel respectively, $Q_{s t}$ is the isosteric heat of adsorption, $m_{w}$ is the mass flow rate of the water.

The importance of heat transfer parameters is described in Eq. (1). These parameters are heat transfer area $A_{\text {hex }}$ and heat transfer coefficient $U_{\text {hex }}$. The left hand side of the adsorber/desorber energy balance equation (Eq. 2) provides the amount of sensible heat required to cool or heat the silica-gel (s), the water (w) as well as metallic (hex) parts of the heat exchanger during adsorption or desorption. In addition, the first term on the right hand side of Eq. (2) stands for the release of adsorption heat or the input of desorption heat, while the second and third terms represent for the sensible heat of the adsorbed vapor. And, the last term on the right hand side of Eq. (2) gives the total amount of heat released to the cooling water upon adsorption or provided by the hot water for desorption. As all beds are assumed to be well insulated, Eq. (2) does not account for external heat losses to the environment.

\section{Energy balance for the evaporator}

In this study, it is considered that the tube bank surface is able to hold a certain maximum amount of condensate and the condensate would flow into the evaporator easily. The heat transfer and energy balance equations [19] for the evaporator can be written as

$$
\begin{aligned}
& T_{\text {eva,out }}=T_{\text {eva }}+ \\
& \left(T_{\text {chill, in }}-T_{\text {eva }}\right) \exp \left(-\frac{U_{\text {hex }} A_{\text {hex }}}{\dot{m}_{\text {chill }} c_{\text {chill }}}\right) \\
& \frac{d}{d t}\left\{\left(w_{\text {eva }, w} c_{w}+w_{\text {eva,hex }} c_{\text {eva,hex }}\right) T_{\text {eva }}\right\}=-L w_{s} \frac{d q_{\text {ads }}}{d t}- \\
& w_{s} c_{w}\left(T_{\text {cond }}-T_{\text {eva }}\right) \frac{d q_{\text {des }}}{d t}+\dot{m}_{\text {chill }} c_{\text {chill }}\left(T_{\text {chill,in }}-\right. \\
& \text { Tchill, out }
\end{aligned}
$$

where, the suffixes chill and eva indicate chilled and evaporator respectively, $\mathrm{L}$ is the latent heat of vaporization.

The sensible heat required by the liquid refrigerant $(w)$ and the metal of heat exchanger tubes in the evaporator can be found from the left hand side of Eq. (4). The first term on the right hand side of Eq. (4) represents the latent heat of 
evaporation $(L)$ for the amount of refrigerants adsorbed $\left(\frac{d q_{a d s}}{d t}\right)$, while the second term gives the sensible heat required to cool down the incoming condensate from the condensation temperature $T_{\text {cond }}$ to evaporation temperature $T_{\text {eva }}$, and the last term indicates the total amount of heat given away by the chilled water.

\section{Energy balance for the condenser}

The heat transfer and energy balance equations ${ }^{19}$ for the condenser can be written as

$$
\begin{gathered}
T_{\text {cond ,out }}=T_{\text {cond }}+\left(T_{c w, \text { in }}-T_{\text {cond }}\right) \exp \left(-\frac{U_{c o n d} A_{\text {cond }}}{\dot{m}_{c w} c_{w}}\right) \\
\frac{d}{d t}\left\{\left(w_{c w, w} c_{w}+w_{\text {cond ,hex }} c_{\text {cond , hex }}\right) T_{\text {cond }}\right\}=-L w_{s} \frac{d q_{\text {ads }}}{d t}- \\
w_{s} c_{w}\left(T_{\text {des }}-T_{\text {cond }}\right) \frac{d q_{\text {des }}}{d t}+\dot{m}_{c w} c_{w}\left(T_{c w, \text { in }}-T_{c w, \text { out }}\right)
\end{gathered}
$$

Mass balance

Mass and heat balances ${ }^{10}$ are based on the assumption that both the temperature and the amount of refrigerant adsorbed are uniform in the adsorbent beds. As the temperatures in an adsorption cycle are unsteady, the energy balance equations (Eqs. 2, 4, and .6) must account for sensible heat input and/or output during the cycle period. The mass balance for the refrigerant can be written as

$\frac{d q_{e v a, w}}{d t}=-w_{s}\left(\frac{d q_{\text {des }- \text { cond }}}{d t}+\frac{d q_{\text {eva }-a d s}}{d t}\right)$

where the subscripts des-cond and eva-ads stand for the refrigerant vapor flows from desorber to condenser and evaporator to adsorber, respectively.

\section{Adsorption rate}

The adsorption rate is expressed as

$\frac{d q}{d t}=\kappa_{s} a_{p}(\dot{q}-q)$

where the overall mass transfer coefficient $\left(\kappa_{s} a_{p}\right)$ for adsorption is considered as

$\kappa_{s} a_{p}=\left(15 D_{s}\right) /\left(R_{p}\right)^{2}$

The adsorption rate is assumed to be controlled by surface diffusion inside a gel particle and surface diffusivity $\left(D_{s}\right)$ is expressed by Sakoda and Suzuki $^{20}$ as a function of temperature by

$D_{s}=D_{s o} \exp \left[-\left(E_{a}\right) /(R T)\right]$

and $\mathrm{q}^{*}$ is the amount adsorbed in equilibrium with pressure $P_{s}\left(T_{w}\right)$ and is derived from the manufacturer property data by the following equation

$q^{*}=\frac{0.8\left[P_{S}\left(T_{w}\right) / P_{S}\left(T_{S}\right)\right]}{1+0.5\left[P_{S}\left(T_{w}\right) / P_{S}\left(T_{S}\right)\right]}$

where $P_{s}\left(T_{w}\right)$ and $P_{s}\left(T_{s}\right)$ are the saturation vapor pressure at temperatures $\mathrm{T}_{\mathrm{w}}$ (water vapor) and $\mathrm{T}_{\mathrm{s}}$ (silica gel), respectively. The saturation vapor pressure and temperature are correlated by Antoine's equation, which can be written as

$P_{S}=133.32 \exp \left(18.3-\frac{3820}{T-46.1}\right)$

\section{Measurement of the system performance}

The performance of a two-stage adsorption chiller using reheat is mainly characterized by cooling capacity (CC), coefficient of performance (COP) and can be measured by the following equationsCC $=\dot{m} c_{w} \int_{0}^{t_{c y c l e}}\left(T_{\text {chill, in }}-\right.$ Tchill, outdt/tcy

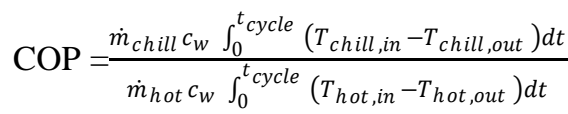

Table 2. Baseline Parameters

\begin{tabular}{|lll|}
\hline \multicolumn{3}{|c|}{ Values Adopted in Simulation } \\
\hline Symbol & Value & Unit \\
\hline $\mathrm{A}_{\text {bed }}$ & 1.45 & $\mathrm{~m}^{2}$ \\
$\mathrm{~A}_{\text {eva }}$ & 0.665 & $\mathrm{~m}^{2}$ \\
$\mathrm{~A}_{\text {con }}$ & 0.998 & $\mathrm{~m}^{2}$ \\
$\mathrm{C}_{\mathrm{s}}$ & 924 & $\mathrm{~J} / \mathrm{kgK}$ \\
$\mathrm{C}_{\mathrm{w}}$ & $4.18 \mathrm{E}+3$ & $\mathrm{~J} / \mathrm{kgK}$ \\
$\mathrm{C}_{\text {chill }}$ & $4.20 \mathrm{E}+3$ & $\mathrm{~J} / \mathrm{kgK}$ \\
$\mathrm{D}_{\text {so }}$ & $2.54 \mathrm{E}-4$ & $\mathrm{~m}^{2} / \mathrm{s}$ \\
$\mathrm{E}_{\mathrm{a}}$ & $2.33 \mathrm{E}+3$ & $\mathrm{~J} / \mathrm{kg}$ \\
$\mathrm{L}$ & $2.50 \mathrm{E}+6$ & $\mathrm{~J} / \mathrm{kg}$ \\
$\mathrm{Q}_{\mathrm{st}}$ & $2.80 \mathrm{E}+6$ & $\mathrm{~J} / \mathrm{kg}$ \\
$\mathrm{R}$ & $4.62 \mathrm{E}+2$ & $\mathrm{~J} / \mathrm{kg}$ \\
$\mathrm{R}_{\mathrm{p}}$ & $0.35 \mathrm{E}-3$ & $\mathrm{M}$ \\
$\mathrm{UA}_{\text {des }}$ & 2532.5 & $\mathrm{Wk}$ \\
$\mathrm{W}_{\mathrm{s}}$ & 16 & $\mathrm{~kg}$ \\
$\mathrm{~W}_{\mathrm{cw}}$ & 5 & $\mathrm{~kg}$ \\
$\mathrm{~W}_{\text {eva,w }}$ & 25 & $\mathrm{~kg}$ \\
\hline
\end{tabular}

Table 3. Standard operating conditions

\begin{tabular}{|c|c|c|}
\hline & Temp. $\left[^{\mathbf{0}} \mathbf{C}\right]$ & Flow rate $[\mathbf{k g} / \mathbf{s}]$ \\
\hline Hot water & 80 & 0.5 \\
\hline Cooling water & 30 & 0.3 (ads) $+0.3($ cond $)$ \\
\hline Chilled water & 14 & 0.3 \\
\hline Cycle Time & $\begin{array}{c}\text { 1800s }=(630 \mathrm{ads} / \mathrm{des}+240 \mathrm{mr}+30 \\
\mathrm{ph} / \mathrm{pc}) \mathrm{s} \times 2 \mathrm{~s}\end{array}$ \\
\hline \multicolumn{2}{|c}{} \\
\hline
\end{tabular}

Ads/des = adsorption/desorption, $\mathrm{mr}=$ mass recovery, $\mathrm{ph} / \mathrm{pc}$ $=$ pre-heat $/$ pre-cool

\section{Solution Procedure}

In the present study, a cyclic simulation computer program is developed to predict the performance of the innovative two-stage chiller using the re-heat scheme. The system of differential Eqs. (1)-(12) (Adsorber/desorber energy balance equations, Evaporator energy balance, Condenser energy balance, Mass balance, Adsorption rate) are solved by employing finite difference approximation with a time step 1 sec. The results taken in the study are from the cyclic steady state conditions. A real chiller starts its function with unbalanced conditions. However, after a few cycles it reaches its cyclical steady state condition. Thus, an iteration process has been used in solution technique to fix all the initial values for the cyclic steady state conditions. From the 
beginning of the solution process, the initial values are considered and lastly those are adjusted by this iteration process.

When two beds are connected with evaporator or condenser, the vapor pressure is unknown that are calculated through the Antonie's equations as the vapor temperature is calculated from the energy balance equation of evaporator or condenser. It is, however, difficult to calculate the saturated vapor calculates the saturated vapor pressure when two beds are connected with each other, which are essential for the calculation of adsorption /desorption rate inside the adsorbent beds. In the state, the pressure is assumed and the amounts of vapor adsorbed/desorbed beds are calculated. Conceptually, the desorbed vapor is equal to the amount of adsorbed vapor by the other beds. If these amounts are not equal then vapor pressure is adjusted for next iteration. Once the satisfactory convergence criterion is achieved, then process goes for the next time step. The convergence criterion for all cases of present study has been taken as 10- 3 .

The sequence of operations for the present work which are used in the computer program is shown in the Fig. 2.

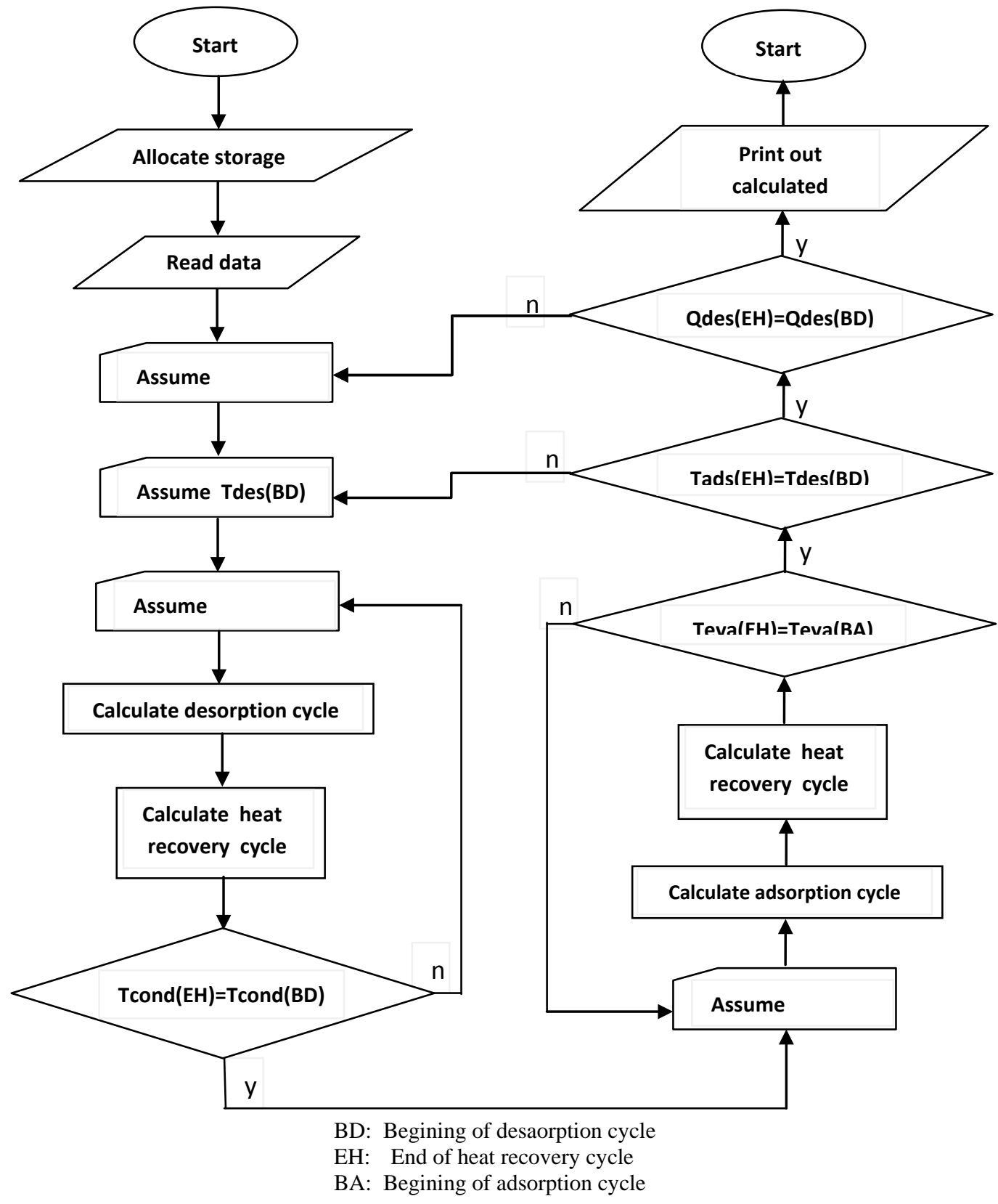

Fig. 2. Computer program-sequence of operations 


\section{Results and Discussion}

In the present treatment, the effect of thermal conductance of evaporator and heat source temperature on the performance of the chiller, chilled water outlet are discussed. It should be noted that the total silica gel mass of the four beds are considered same. However, the mass ratio of upper bed and lower bed are kept 3:2 fixed.

From Figs. 3 and 4, it is seen that CC and COP increase when both UA of evaporator and heat source temperature increase. It is observed that both CC and COP increase up to its maximum value where the value of UA of evaporator is equal to $2989.9 \mathrm{~W} / \mathrm{K}$. So, UA value of evaporator greater than $2989.9 \mathrm{~W} / \mathrm{K}$ is no longer effective for the present baseline condition.

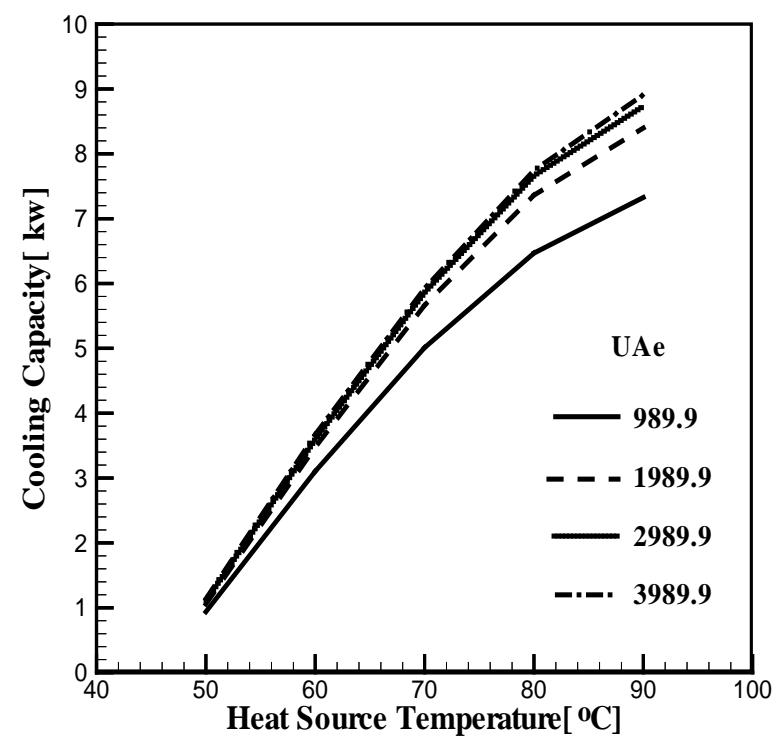

Fig. 3. Effect of Thermal conductance [UA] of evaporator on cooling capacity

In an adsorption chiller, the chilled water for air-condition purposes is obtained from the outlet of the chilled water. Generally, less chilled water outlet temperature is expected, while the requirement of cooling capacity is high. The chilled water outlet temperature, however, affects cooling demand of the demand side. Therefore the requirement of chilled water outlet temperature is very important. From this context, the effect of heat source temperature as well as UA of evaporator is presented in Fig. 5. It may be seen that the chiller with different level heat source temperature provides different level chilled water outlet temperature. It can be also seen that the higher is the heat source temperature; the lower is the chilled water outlet temperature.

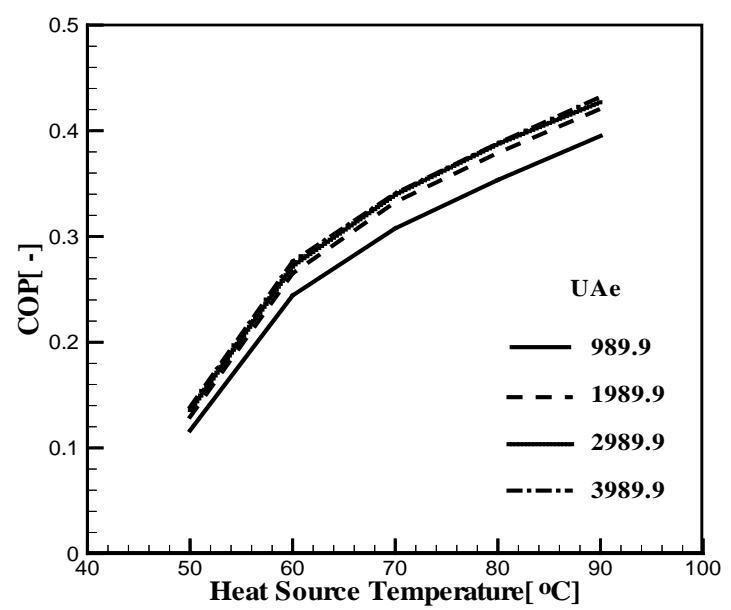

Fig. 4. Effect of Thermal conductance [UA] of evaporator on cooling capacity

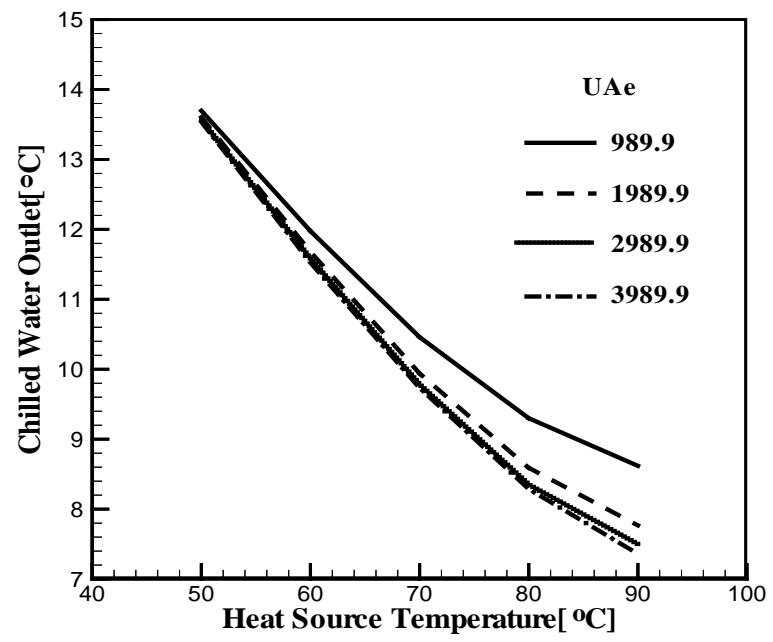

Fig. 5. Effect of thermal conductance of evaporator on chilled water outlet performance

\section{Conclusions}

In this study, the effect of thermal conductance of evaporator on the performance of a two-stage adsorption chiller with re-heat scheme has been investigated numerically. A finite difference iterative technique is used in the analysis for the solution procedure and mass ratio of upper and lower bed is kept 3:2 fixed. Through analysis, calculations can be drawn as follows.

- As the heat source temperature increases, CC and COP increase. However, chilled water outlet is decreased.

- For large values of thermal conductance of evaporator, the system gives better performance.

- Chilled water outlet decreases, as the thermal conductance of evaporator and heat source temperature increase. 


\section{References}

1. Karagiorgas, M., F. Meunier,1987. The dynamics of a solid adsorption heat pump connected with outside heat sources of finite capacity, J. Heat Recovery Systems CHP, 7(3), 285299.

2. Critoph, R.E., Vogel, 1986. Possible adsorption pairs for use in solar cooling, Int. J. Ambient Energy, 7(4), 183-190.

3. Critoph, R.E., 1989. Activated carbon adsorption cycles for refrigeration and heat pumping, Carbon, 27(1), 63-70.

4. Boelman, E.C. B.B. Saha, T. Kashiwagi, 1995. Experimental investigation of a silica-gel water adsorption refrigeration cycle the influence of operating conditions on cooling output and COP, ASHRAE Trans Res, 101(2), 358-366.

5. Meunier, F., 1986. Theoritical performance of solid adsorbent cascading cycles using the geolite- water and active carbonmethanol pairs: four case studies, Heat Recovery CHP system, 6(6), 491-498.

6. Shelton, S. V., J.W. Miles, 1990. Ramp wave analysis of the solid-vapor heat pump, ASME J. Energy Resources Technology, 112, 69-78.

7. Critoph RE, 1998. Forced convection adsorption cycles. Appl Thermal Engng, 18,799-807.

8. Pons, M., F. Poyelle, 1999. Adsorbtive Machines with advantaged cycles for heat pumping or cooling Applications, Int. J. Refrigeration, 22(1), 27-37.

9. Wang RZ, 2001. Performance improvement of adsorption cooling by heat and mass recovery operation. Int $\mathrm{J}$ Refrigeration, 24,602-11.

10. Saha, B.B., E. C. Boelman, T. Kashiwagi, 1995. tComputational analysis of an advanced adsorption refrigeration cycles, 20, 983-994.

11. Saha, B.B., K. C. A. Alam, A. Akisawa and T. Kashiwagi, K. C. Ng, H.T. Chhua, 2000. Two stage non-regenerative Silica gel/ water adsorption refrigeration cycles, in: Proceeding of the ASME advanced enery systems division, Orlando, FL, USA, 40, 65-69.
12. Alam K. C. A., Y. Hamamoto, A. Akisawa, T. Kashiwagi, 2003. Advanced adsorption chiller driven by low temperature heat source, in: Proceedings of $21^{\text {st }}$ International Congress of Refrigeration: Paper no. 0136 in CD ROM Washington DC, USA $17-22$

13. Khan M.Z.I., K.C.A. Alam, B.B. Saha, Y. Hamamoto, A. Akisawa and T. Kashiwagi, 2006. Parametric study of a twostage adsorption chiller using re-heat-The effect of overall thermal conductance and adsorbent mass on system performance, Int. Journal of Thermal Science, 45, 511-519.

14. Khan M.Z.I., K.C.A. Alam, B.B. Saha, A. Akisawa and T. Kashiwagi, 2008. Performance evaluation of multi-stage, multi-bed adsorption chiller employing re-heat scheme, Renewable Energy, 33, 88-98.

15. Saha B. B., A. Akisawa, T. Kashiwagi, 1997. Silica gel water advanced adsorption refrigeration cycle, Energy, 22(4), 437-447.

16. Farid S.K., M.M. Billah, M.Z.I. Khan , M.M. Rahman, M.U. Sharif, 2011. A numerical analysis of cooling water temperature of two-stage adsorption chiller along with different mass ratio, Int. Communications in Heat and Mass Transfer, 38(8), 1086-1092.

17. Alam, K.C.A., Y. Hamamoto, A. Akisawa, T. Kashiwagi, 2003. Advanced adsorption chiller driven by low temperature heat source, Proceeding of $21^{\text {st }}$ International Congress of refrigeration (CD ROM), Washington, DC, 136.

18. Akahira A., K.C.A. Alam, Y. Hamamoto, A. Akisawa, T. Kashiwagi, 2005. Experimental investigation of mass recovery adsorption refrigeration cycle, Int. J. Refrig.28, 565-572.

19. Srivastava, N. C., I. W. Eames, 1997. A review of solidvappor adsorption refrigeration and heat pump system developments. Journal of the Institute of Energy, 70, 116-127.

20. Sakoda, A., M. Suzuki, 1984. Fundamental study on solar powered adsorption cooling system. Journal of Chemical Engineering of Japan, 17, 52. 